\title{
Chapter 43 \\ Equity in Mathematics Education: \\ What Did TIMSS and PISA Tell Us \\ in the Last Two Decades?
}

\author{
Yan Zhu
}

\begin{abstract}
Equity in education has been a concern of almost all countries, whether developed, transitional, or in the progress of developing. It is believed that unequal education implies that human potential is being wasted. The present study focused on students with different characteristics as aggregate groups in an examination of similarities and differences in mathematics learning. The information analyzed here was mainly based on data from TIMSS and PISA databases. This investigation aims to paint an overall picture about gender equity, socioeconomic status, and indigenity equity in mathematics education over the last twenty years. It is hoped that the study can provide useful insights to individual education systems and further help them to identify more promising practices to narrow or even eliminate the existing between-system as well as within-system gaps.
\end{abstract}

Keywords Gender equity - Socioeconomic status equity $\cdot$ Immigrant background equity · PISA · TIMSS

\subsection{Equity in Mathematics Education}

Equity has been on the agenda of mathematics education research for at least four decades. For instance, Fennema's (1974) seminal work was about male-female differences in mathematics achievement and Fennema and Sherman (1977) approached the topic via affective perspectives. In the first Handbook of Research on Mathematics Teaching and Learning (Grouws 1992), there are two chapters dealing with this issue. Year 1995 witnessed the publication of two books that concerned research on equity within mathematics education (Rogers and Kaiser 1995; Secada et al. 1995). Pais (2012) noted that this interest in equity has proliferated theories in mathematics education research that progressively deemphasized cognitive psychology as an interpretative framework for mathematics learning

\footnotetext{
Y. Zhu $(\bowtie)$

East China Normal University, Shanghai, People's Republic of China

e-mail: yzhu@kcx.ecnu.edu.cn

(C) The Author(s) 2018

G. Kaiser et al. (eds.), Invited Lectures from the 13th International Congress

on Mathematical Education, ICME-13 Monographs,

https://doi.org/10.1007/978-3-319-72170-5_43
} 
in favor of more socio-cultural oriented frameworks. Consistently, Gutiérrez (2010) has claimed that "sociocultural theories, once seen on the fringe of a mainly cognitive field, now take their place squarely within mainstream mathematics education journals like JRME" (p. 2). The National Council of Teachers of Mathematics, in Principles and Standards for School Mathematics (NCTM 2000), identifies as its first guiding Principle that "Excellence in mathematics education requires equityhigh expectations and strong support for all students" (p. 11).

While the growing attention to equity in mathematics education promotes 'talk' of equity becoming more mainstream in the mathematics education community (Gutiérrez and Dixon-Roman 2011), the term often has different meanings to different people. In fact, when referring to educational equity, the term equality is often used interchangeably. It can be seen that the two terms have close similarities but with important distinctions. The Oxford English Dictionary defines equity as "the quality of being fair and impartial" and equality as "the state of being equal, especially in status, rights, or opportunities". Based on these two definitions, the former appears to be more about being impartial with the latter more about being the same. In this sense, differences related to individual needs and requirements are recognized and treated in the notion of equity; in contrast, everyone will be regarded and treated in the same manner without focusing on specific needs and requirements in the notion of equality.

Regarding the subject of mathematics, NCTM (2000) has highlighted that equity does not mean that every student should receive identical instruction; instead, reasonable and appropriate accommodations should be made to promote access and attainment for all students. Similarly, Secada (1989) argued that the two notions are not synonymous, remarking that rather than striving for equality, people should work towards equitable inequalities that reflect the needs and strengths of individuals. In fact, as Volmink (1994) described mathematics as a field that is the "sole creation of a few, singularly brilliant ... individuals" (p. 51), it is unrealistic to expect all individuals to achieve equally in this elitist field. Correspondingly, it would become more important and meaningful to investigate the source of the differences as well as identify the reasons underlying so as to pursue equitable inequalities that reflect individuals' specific strengths and needs.

Arnaud (2001) and Arnesson (2001), respectively, did some concise analyses on equity and equality in a more general sense, and their work problematized the conceptualization of the two notions. Arnaud commented that, due to being associated with fairness and impartiality, the notion of equity could possibly be regarded as a means to bring harmony into progressive societies and/or solve conflicts in some legal cultures. Arnesson, on the other hand, proposed that, as equality has been linked to the basic idea of being the same, it could bring up with two issues: one is about who should be the same and the other is about how important to be the same. Although there exist ambiguities and disagreements with respect to the two notions, Arnaud (2001) pointed out that the relationship between them appears to be a newly contemporary and significant notion (also see Herrera 2007). To a certain extent, this idea supports Hutmacher's (2001) call for the need of a clear conceptual framework with the potential to be a starting point in studying equity and equality. 
Not only are there similar concepts to equity, but also the notion itself can be understood in many different ways. For instance, the Organization for Economic Cooperation and Development (OECD) defines equity in education through two dimensions: fairness and inclusion (Field et al. 2007). This suggests that, by fairness, equity implies ensuring that personal and socio-economic circumstances (e.g., gender, ethnic origin, family background) should not be obstacles to achieving education potential, while by inclusion, it implies ensuring all students to reach at least a basic minimum level of skills. It shall be noted that the two dimensions are closely intertwined. More specifically, equitable education is expected to support students to reach their learning potential without either formally or informally pre-setting barriers or lowering expectations (OECD 2012). In this sense, tackling school failure may help to overcome the effects of social deprivation, which often causes school failure (Field et al. 2007).

The NCTM research committee also remarks that there are multiple concepts encompassed in the notion of equity and they can be classified into either conditions of learning or the outcomes. According to Lipman (2004), the former can be described as "equitable distribution of material and human resources, intellectually challenging curricula, educational experiences that build on students' cultures, languages, home experiences, and identities, and pedagogies that prepare students to engage in critical thought and democratic participation in society" (p. 3). From the perspective of outcomes, Gutstein (2000) defined equity as "obliterating the differential and socially unjust outcomes in mathematics education" (p. 26). The mentioned outcomes could include students' achievement and participation in mathematics, their powers of analyzing and reasoning, and their abilities to "critique knowledge or events" (Gutstein et al. 2005).

Brown (2006) differentiated equity into horizontal equity and vertical equity. Correspondingly, horizontal equity refers to equal treatment of those who are similar to each other and vertical equity refers to unequal but equitable treatment of those with different needs, which is designed to reduce inequality. It is suggested that horizontal equity is a starting point that can be used to help achieve vertical equity. In this sense, vertical equity will look into whose situation can be improved, and then how to make the improvement.

Gutiérrez (2009) proposed a four-dimension model for the notion of equity in mathematics learning including: access, achievement, identity, and power. In particular, access relates to the tangible resources that students have available to them to participate in mathematics, and achievement refers to observable results for students at all level of mathematics. The two were further characterized by Gutiérrez as the dominant axis of equity, which measure how well students "play the game" of mathematics as it currently stands. Moreover, access is suggested to be a precursor to achievement. The dimension identity concerns not only students' pasts (e.g., the contributions of their ancestors), but more about a balance between themselves and others. In other words, students need to have opportunities to see themselves reflected in the curriculum while having a view onto a broader world. The issue of power is raised because equity is more than having students "be themselves and better themselves" via doing mathematics. According to Gutiérrez 
(2007), it cannot be called equity if mathematics as a filed and/or people's relationship has no changes. Gutiérrez further proposed identity and power to make up the critical axis of equity, as they challenge the static formalism embedded in traditions. This axis relates to students' ability to "change the game". On this axis, identity can be regarded as a precursor to power.

Although there are different understandings and interpretations about the notion of equity, it is suggested that the relevant research in mathematics education can be used to help in understanding the causes for the inequalities and identifying strategies to reduce the disparities and the effects of these inequalities (Rohn 2013). Furthermore, some researchers have even claimed that only focusing on equity and equality is not enough, and additional attention should be further given to liberation. Liberation refers to working to challenge and reverse the effects of structural oppression in society. No matter what standpoints people take, it has generally been believed that high performing education systems are those that combine equity and quality, where all students are given opportunities for a good quality education.

\subsection{Factors Contributing to Inequity in Education}

There are many factors that may influence inequitable opportunities and outcomes in education, such as gender, income and socio-economic status, ethnicity, indigeneity, culture, religion, language, geographical location, etc. (Wood et al. 2011). Different countries usually would use different sub-sets from this set of categories to define diversity, and assess how equitable their education systems are. Among these factors, gender, typically, appeared to be the most widely used category (Clancy and Goasstellec 2007).

Within the field of mathematics education research, gender was historically the initial dimension of equity researched widely, and later served as the springboard for emphases on, or in combination with, the other dimensions of equity (Forgasz and Rivera 2012). In earlier times, a wide range of international research studies reported gender inequities, with most favoring males. For instance, Maccoby and Jacklin's (1974) review of close to 1600 studies of gender differences concluded that boys were better in mathematics and physical sciences, whereas girls were better in reading and writing. Later reviews, adopting more sophisticated meta-analytical techniques, consistently reported similar patterns of gender difference, although the magnitudes of the differences were smaller (e.g., Wider and Powell 1989; Willingham and Cole 1997). In fact, mathematics was traditionally stereotyped as a male domain and societal influences tended to suggest that mathematical learning was not particularly appropriate for girls (e.g., Damarin 1995; Fennema 2000; Leder 1992).

In order to explain the potential gender gap in mathematics learning, various theories have been explored (see Wider and Powell 1989). One strand of such explorations looks into biological differences to support innate differences in spatial ability, higher order thinking, or brain development. Nevertheless, some researchers 
have pointed out that such differences are small and their relationships with mathematics test performance are tenuous (e.g., Guiso et al. 2008). Kane and Mertz (2011) further argued that if gender differences are primarily a consequence of innate, biologically determined differences, they should be expected to be similar across countries, regardless of culture, and should remain constant across time. Another strand of research emphasizes societal factors, highlighting how girls are socialized into believing that mathematics is not important, useful, doable, or part of a girl's identity. For instance, West and Zimmeran (1987) remarked that a person's gender is not simply an aspect of what one is, but more fundamentally it is something that one does recurrently in interaction with others; they called this "doing gender". According to Kaiser (2003), the social construction of gender forms the theoretical base of many empirical studies on the relationship between gender and mathematics.

In more recent studies, however, researchers have observed that the gender differences in mathematics have not only narrowed substantially over time, but sometimes have even been eliminated (e.g., Halpern et al. 2005; Hyde and Mertz 2009; Spielman 2008). In fact, there are some researchers who have started including boys' educational needs into their work on gender (e.g., Forgasz and Leder 2001; Lingard et al. 2002; Weiner et al. 1997). Regarding the complexity of the gender gap in mathematics achievement, Ellison and Swanson (2010) attributed it to the differences that exist between tests and systems.

Compared to gender, students' socioeconomic status (SES) was not enunciated as a problem in the field of mathematics education until the 1980s, when the "social turn" was advanced (Lerman 2000, 2006). Since the 1990s, the number of studies investigating the relation between SES and students' mathematics achievements has increased, with growing importance given to periodic, international, standardized, comparative studies as TIMSS and PISA (Valero and Meaney 2014). On the other hand, studies investigating the connection between people's social and economic position and school achievements emerged much earlier, at the beginning of the 20th century (see Valero et al. 2015). The Coleman Report (Coleman et al. 1966) was one of the first large scale national surveys that acknowledged socioeconomic status as a major predictor of educational achievement (Knapp and Woolverton 2004).

No matter whether it is education in general, or specific to mathematics education, the existing research consistently demonstrates a positive correlation between students' socioeconomic status and their academic achievement level. Such findings have been reported in both international large-scale assessments, and school level assessments. Sirin's (2005) meta-analysis on SES and academic achievement in journal articles published between 1990 and 2000 revealed a medium to strong association. Rothman and McMillan (2003) further identified that the relationship within schools was relatively small, although significant; while that between schools was much larger and significant. 
Following the "age of migration" (Castles and Miller 2003), many countries now host a substantial and growing population of immigrants, a considerable number of whom are children. Consequently, immigrant children's educational performance has become one of policymakers' core concerns. The observations that the educational performance of children with an immigration background often differs from that of their host countries, and is also different from their countries of origin; these two important macro-level factors invite explanations. At the individual level, the relevance of classic background attributes for explaining the educational achievement of immigrant children has been well documented (Kao and Thompson 2003). Some frequently mentioned attributes include socioeconomic status, parental income, and cultural capital (e.g., number of books at home), language spoken at home, and age of arrival in the host country.

Focusing on the learning of mathematics, it is suggested that there is a lot to learn for a newcomer, and the least problematic may be mathematics (Bishop 2006). Besides the subject, a learner's mathematics practices would be shaped and negotiated by classroom participants with various levels of shaping power. In particular, classroom teachers have power of the formal and institutional kind, classmates or peers play a fundamental role at the level of being near equals, that is, equality between the one who chooses to exercise influence and the one who is chosen to be influenced. In some sense, the learner has the most power over his/her own learning, such as choosing how much effort to expand, whom to listen to, and whose views to respect. Moreover, the learning is also a product of the learner's cultural and social history, shaped in large by his/her family life and outside-school life experiences. In this regard, parents are particularly influential.

While a variety of factors at different levels (i.e., macro, mezzo, micro) could cause inequality in education, it should be noted that the inequalities and injustices often do not work in isolation, but rather a combination of two or more of this diversity of dimensions. For instance, the status of being poor and living in a rural area could increase disadvantage several times over (Morely et al. 2009; UNESCO 2008). Moreover, in many countries, some of these factors have clear historical roots and trajectories. Consequently, co-occurrences of low achievement among some ethnic minority groups and those of low socio-economic status are then not unusual. In fact, in some countries that were regarded as 'highly developed', structural inequalities also existed (United Nations Development Program 2009). For instance, in the UK and the US, ethnicity and low socioeconomic status appeared to be two of the main risk factors for students' underperformance in schools. While a list of such contributory attributes is far from exhaustive, identifying causal relations between the sources and consequences of educational disadvantage is important for making effective policy recommendations. 


\subsection{What Do TIMSS and PISA Tell About Equity in Mathematics Education?}

\subsubsection{TIMSS Versus PISA}

The Trends in International Mathematics and Science Study (TIMSS) is one of the studies established by the International Association for the Evaluation of Educational Achievement (IEA). It aims to measure the extent to which students have mastered the topics and skills as appeared in school curricula. A Pilot TwelveCountry Study, conducted in 1959 to 1962, was the very first IEA study, and increasingly more education systems participated in its later cycles. The term TIMSS first appeared in 1995, known as the Third International Mathematics and Science Study, and was renamed the Trends in International Mathematics and Science Study in 1999 and onwards. Meanwhile, the series of studies were conducted in regular four-year cycles from 1995. The most recent study was TIMSS 2015 with more than 60 systems participating. In most of the cycles, 4th and 8th graders' achievement in mathematics and science were assessed. TIMSS uses the curriculum as its major organizational aspect. Three curriculum layers are envisaged: intended curriculum (i.e., the subject intended for students to learn, and how the education system should be organized to facilitate this learning); implemented curriculum (i.e., what is actually taught in the classroom, who teaches it, and how is it taught); and attained curriculum (i.e., what it is that students have learned, and what they think about the subject).

The Program for International Student Assessment (PISA) is another worldwide large-scale study, which is under the auspices of the Organization for Economic Co-operation and Development (OECD). It aims to look “at young people's ability to use their knowledge and skills in order to meet real-life challenges rather than how well they had mastered a specific school curriculum" (OECD 2005, p. 9). The PISA study series was first implemented in 2000 and then repeated every three years. The most recent was PISA 2015, with 71 countries/economies participating. Due to its focus on the practicalities of students' skills, PISA uses the term literacy referring to "the capacity of students to apply knowledge and skills in key subject areas and to analyse, reason and communicate effectively as they pose, solve and interpret problems in a variety of situations".

Coessens et al. (2014) differentiated the two international large-scale studies from four perspectives. The first is that TIMSS focuses on curriculum-related tasks, while PISA is literacy based. This links to the second difference, that is, TIMSS items are more knowledge oriented, while PISA items are aimed at life skills. Third, TIMSS focuses on the extent to which students have mastered mathematics and science as they appear in school curricula, while PISA aims to capture the ability to use mathematical and scientific knowledge and skills to meet real-life challenges. In short, TIMSS focuses more on pure mathematical performance, while PISA focuses more on the practicalities of mathematical skills. Fourth, TIMSS is explicitly organized around two frameworks, a curriculum framework and an assessment 
framework, while PISA focuses on skills for future life rather than on the grasp of the school curriculum. There are also researchers differentiating the two studies from the perspective of targeted populations. For instance, Harlen (2001) highlighted that while TIMSS assessed the progress of students at particular grade levels, and so at different ages for countries, PISA was concerned with 15-year-old students' performance as an indicator of the outcomes of compulsory education. Similarly, Lester (2007) summarized the difference as TIMSS holding a grade-specific structure versus PISA holding an age-specific structure.

Regarding the issue of equity, it appears that PISA gives it more explicit attention. In particular, PISA defines the notion of equity as "to provide all students, regardless of gender, family background or socio-economic status (SES), with opportunities to benefit from education" (OECD 2013a, p. 13). In this sense, equity implies more than everyone having the same results, but everyone, regardless of his/her background, should be offered access to quality educational resources and opportunities to learn. As a result, one's gender, SES, or immigrant background should then have little or no impact on his/her performance. The following sections of this chapter will focus on what TIMSS and PISA have found regarding equity in mathematics education in the last two decades, from the perspectives of three important personal background aspects: gender, socioeconomic status, and immigrant background.

\subsubsection{Gender Equity}

Gender equity has become one of the most prominent issues in education reform efforts worldwide, with international organizations and governments having increasingly recognized that gender equity strengthens democracy, and serves as a hallmark of an inclusive society that values and capitalizes on the contributions of all its members.

Related to the subject of mathematics, gender has always been an issue of concern that is investigated in the IEA study series. As early as in the Pilot TwelveCountry Study (13-year-olds), girls were, in general, observed to be outperformed by boys. In the First International Mathematics Study (FIMS), Keeves (1973) found that boys performed better than girls in all ten original FIMS countries in terms of overall mathematics achievement, with some variations in the magnitudes of the differences at the 13-year-old level (Population I) across the countries. Based on the data from all the twelve FIMS countries, Steinkamp et al. (1985) again reported that boys outperformed girls in 10 countries in overall mathematics achievement, and in eight countries the differences reached statistical significance. Husén (1967) further claimed that while the gender differences in favor of boys appeared to be a global phenomenon, the differences in favor of girls were observed within some countries, although overall, the differences were insignificant. Besides test performance, Steinkamp et al. further identified three important contextual variables for gender differences in mathematics learning including: student 
attitudes, the opportunity to learn, and the amount of homework. Compared to the differences at the secondary school level, those at the pre-university level (Population II) were greater (Keeves 1973). Harnisch et al. (1986) suggested that the gender differences were pervasive across cultures, and that non-biological factors played a role in determining the magnitudes.

Interestingly, the terms used in the discussion of differences between the sexes changed from FIMS to SIMS (Second International Mathematics Study), with "gender differences" gaining prominence over "sex differences". Hanna (2000) argued that such a change may imply that "gender" could be a term more appropriate for describing psychological, social, attitudinal, and cultural characteristics, while "sex" could be one reserved for immutable biological characteristics. The SIMS revealed that boys outperformed girls significantly in seven out of the 19 countries, girls outperformed boys significantly in four, and no significant gender differences were found in the remaining eight countries (Baker and Jones 1993). Based on the results, Baker and Jones pointed out that the gender differences in SIMS varied in both size and direction among countries. Furthermore, Hanna (2000) claimed that while the gender differences varied widely from country to country, between-country differences were smaller than within-country ones.

In the Third International Mathematics and Science Study (TIMSS) at the fourth grade, the mathematics achievements in most countries were approximately the same for boys and girls, although in three countries statistically significance differences were found in favor of males. Similarly, the differences at the eighth grade level were also small or negligible overall. However, all the statistically significant differences were consistently found to favor male students (in eight countries). A rather different finding was revealed at the twelfth grade, where males in most countries had significantly higher average achievement than females in both mathematics literacy and in advanced mathematics.

Based on the review of gender differences in mathematics achievement from FIMS to SIMS to TIMSS, Hanna (2003) proposed "the end of gender differences" (p. 209). According to Baker and Wiseman (2005), among the countries participating in only the 1960s and 1990s assessments, and those in just the 1980s and 1990 s assessments, the proportion of countries with statistically significant male-dominated gender differences in mathematics scores declined from 33 to $9 \%$ from the 1960s to 1990 s, and from 35 to $18 \%$ from the 1980 s to $1990 \mathrm{~s}$.

Such a diminishing tendency further continued in the later TIMSS studies. In particular, most of the gender differences found in TIMSS 1999 were negligible, and no country showed a significant increase in difference over time. In TIMSS 2003, gender differences in favor of girls matched gender differences in favor of boys in terms of number and magnitude. TIMSS 2007 revealed negligible gender differences at the fourth grade in roughly half of the participating countries; in the remaining countries, girls had higher achievement in about half and boys had higher achievement in the other half. Interestingly, at the eighth grade, TIMSS 2007 found that, on average, girls had higher achievement than boys. In TIMSS 2011, female fourth graders' average mathematics score was only 1 point lower than that of male students, while female eighth graders' average mathematics score was 4 points 
higher than that of male students. Moreover, at the fourth grade, of the 50 participating countries, about 24 had significant gender differences with all but four in favor of boys; at the eighth grade, of the 42 countries, about 20 had significant gender differences, with seven favoring boys and 13 favoring girls.

While TIMSS is more concerned about school curriculum related mathematics achievement, PISA focuses on everyday skills-related mathematics achievement. Based on the PISA data, Forgasz and Hill (2013) argued that the gap between boys and girls on mathematics literacy had widened. It can be seen that in the first PISA study, boys tended to perform at somewhat higher levels in most countries, with an average gap of 11 points, and 17 out of the 42 participating countries $(40.5 \%)$ revealed statistically significant differences in favor of boys. The PISA 2003 mathematics assessment consistently revealed an overall gender difference of 11 score points in favor of boys. Of the 41 participating countries, 27 (65.9\%) revealed a gender difference in favor of boys, and one with a difference in favor of girls. PISA 2006 similarly revealed more than $60 \%$ of the participating countries (35 out of 57) having boys outperforming girls in mathematical literacy at a significant level. In both PISA 2009 and PISA 2012, the proportions of countries with an advantage in favour of boys in mathematics literacy went down to $61.4 \%$ and $56.9 \%$, respectively. Researchers claimed that a wider gender gap among the least and most able students was actually masked (OECD 2013b). In fact, in most countries, the most able girls lagged behind the most able boys. For instance, in PISA 2009 it was found that only $3.4 \%$ of girls compared to $6.6 \%$ of boys were at the top performance in mathematics literacy.

Based on both the TIMSS and PISA databases, Baye and Monseur (2016) analyzed gender differences, from an international perspective, from 1995 to 2015 via the use of effect sizes and variance ratios. The results showed that the sizes of the gender differences varied according to student proficiency levels. In particular, at the lower tail of the distribution, effect sizes were close to zero or in favor of girls, while systematically at the upper tail, boys were more proficient. The largest gender difference in mathematics literacy was observed on PISA 2003 for the most proficient students (i.e., percentile 95). Baye and Monseur claimed that such a tendency was more obvious at the secondary level of education, and in PISA rather than in TIMSS. In fact, at the eighth grade level, the TIMSS data revealed that the tendency for boys to outperform girls at the upper end of the distribution had decreased over time, which is consistent with the overall pattern.

\subsubsection{Socioeconomic Status Equity}

Regarding students' socioeconomic status, PISA constructs a composite index, Economic, Social and Cultural Status (ESCS), which is derived from three variables related to family background: highest level of parental education, highest parental occupation, and the number of possession in the home. While information about parental education and home possessions were also collected in TIMSS, the 
study constructed a composite index in a less consistent way. In particular, TIMSS 1999 and TIMSS 2011 created an index of Home Educational Resources (BSDGHER), while in other years the emphasis in the investigation was more focused on the item base.

In general, no matter whether the influence of students' socioeconomic status on their mathematics achievement was investigated via individual items or via a composite index, all the TIMSS studies consistently revealed that students having more books in the home and parents with more education achieved better scores in mathematics. This pattern was observed in all of the participating countries and in all of the years. On the other hand, the data also revealed that students at the high level of Home Educational Resources were relatively rare in most countries. In TIMSS 1999, there were just $9 \%$ of eighth graders in this category on average, and their mathematics achievement was 109 score points higher than those in the low category (19\%). Similarly, in TIMSS 2011, about $17 \%$ of fourth graders were in the high category (i.e., many resources), and their mathematics achievement was 109 score points higher than those in the low category (i.e., few resources: 9\%); about $12 \%$ of eighth graders were in the high category and their mathematics achievement was 107 score points higher than those in the low category $(20.5 \%)$.

PISA 2003 shows that although poor performance in school does not automatically follow from a disadvantaged home background, home background remains one of the most powerful factors influencing performance. The average performance gap in mathematics between students in the top quarter of the PISA index of occupational status and those in the bottom quarter amounts to an average 93 score points, which is more than one-and-a-half proficiency levels in mathematical literacy. PISA 2012 confirms that in all countries, students from socioeconomically disadvantaged backgrounds show lower levels of mathematics achievement than their better-off peers. In particular, the performance difference between the advantaged (the top quarter of socio-economic status) and the disadvantaged (the bottom quarter of socio-economic status) students is 90 score points, which is equivalent of more than two years of schooling and more than one PISA proficiency level.

In order to investigate the influence of students' socioeconomic status on their mathematics achievement in both TIMSS and PISA, Adamson (2010) constructed the SES index for TIMSS which mirrored the PISA index, although only including the variables for home possessions and parental education, followed by assigning students to SES quintiles. Taking national economic conditions into account, Adamson found that when income per capita increases, students' mathematics achievement also increases for both low and high SES students. However, the achievement differences between the two groups of students remained large. In particular, the difference is about one SD on PISA 2003 and nearly three-quarters of a SD on TIMSS 2003. Furthermore, the study revealed that country-level income inequity interacted with SES in a way that partially negated the SES significance on PISA. Comparatively, a straightforward relationship between income inequality and achievement was shown on TIMSS, with increasing income inequality correlating significantly with lower mathematics achievement in all models. In addition, as 
income inequality increased, high SES students achieved even higher mathematics scores than their lower SES peers.

\subsubsection{Immigrant Background Equity}

While both TIMSS and PISA ask students about their birthplaces, as well as their parents', the two study series look into the issue in different ways. In particular, PISA identified three immigrant backgrounds including: native students (who have at least one parent born in the country of assessment), second-generation students (who were born in the country of assessment but whose parents were foreign-born), and first-generation students (who were foreign-born and whose parents were also foreign-born). TIMSS also classified three immigrant backgrounds but with parents' birthplaces being the main indicators: native students (both parents born in the country of assessment), half-and-half immigrant students (one parent born in the country of assessment), and immigrant students (neither parent born in the country of assessment).

Hastedt (2016) adopted PISA's immigrant definitions to analyze trends in the percentages of immigrant students in both fourth and eighth grades, as well as achievement differences between immigrant and native students using TIMSS data from the 1995 to 2007 cycles. The results showed that for both grade levels, the percentage of immigrant students increased incrementally over the years. In particular, the first-generation immigrant population increased between 1995 and 2007 in a large number of countries. Regarding students' mathematical literacy performance, the data overall revealed that immigrant students were outperformed by native students. For instance, in TIMSS 1995, native eighth grader students significantly outperformed first-generation immigrant students in 17 out of 37 countries $(46 \%)$, as well as second-generation immigrant students in 10 countries $(27 \%)$. The corresponding percentages of countries in TIMSS 1999, TIMSS 2003, and TIMSS 2007 were 32 and 16\%, 76 and 31\%, and 76 and 38\%, respectively.

PISA 2012 reported that across OECD countries, $11 \%$ of the students had an immigrant background and they tended to be socioeconomically disadvantaged in comparison to their native peers (OECD 2015). In the mathematical literacy assessment, the students with immigrant background scored an average of 34 points lower than native students, and an average of 21 points lower after accounting for socioeconomic differences. In fact, immigrant students are 1.70 times more likely than native students to perform in the bottom quarter of the performance distribution. The achievement differences were even larger in PISA 2003, although the percentage of students across OECD countries who had an immigrant background was slightly lower (9\%). In that year, immigrant students scored 47 points lower in mathematical literacy than their native peers, and 33 points lower when controlling for socioeconomic status. There is one promising finding from the comparison 
between PISA 2003 and PISA 2012: immigrant students' socioeconomic status profile was slightly more advantaged than that of immigrant students in 2003 . This appears to suggest that, on average across OECD countries, immigrant students face less socioeconomic and performance disadvantage. On the other hand, the significant disadvantage in mathematical literacy performance was still evident among immigrant students in PISA 2012.

Andon et al. (2014) did a quantitative synthesis of the immigrant achievement gap across OECD countries using data from both TIMSS and PISA between 2000 and 2009. The study found a significant mean effect size for mathematics $(\mathrm{d}=0.38)$. Moreover, the analysis revealed a larger gap in TIMSS than PISA. Andon et al. argued that this may be due in part to the type of content assessed, that is, TIMSS evaluated formal mathematics knowledge, and PISA items are more applied in nature and posed within real-world scenarios which require mathematics. They suggested that immigrant students fared better on items that tell a story, provide more context, and allow them to apply their experience and knowledge, as in the PISA. Consequently, immigrant students performed less poorly on PISA than on TIMSS relative to native students.

\subsubsection{Concentration of Disadvantages Related to Inequity}

It is suggested that underperformance of students with particular personal characteristics can be partly linked to the fact that these students tend to be concentrated in groups. For instance, immigrant students may settle in neighborhoods with other immigrants when they move to a new country. Similarly, students with low socioeconomic status may also more often group together. The potential result of such a concentration is that large differences in student performance are likely to exist at both the school and national levels.

Focusing on mathematics, two cross-national comparisons in students' achievement outcomes have been conducted on the TIMSS and PISA, respectively. With the analysis of the data from TIMSS 1995, TIMSS 1999, TIMSS 2003 and TIMSS 2007, Zopluoglu (2012) found that the proportions of differences that occurred at the student level were, in general, decreasing at both the fourth and eighth grade levels. For instance, there was about $58 \%$ of the difference in fourth graders' mathematics achievement related to students' individual differences in TIMSS 1995, and the percentage decreased to $25 \%$ in TIMSS 2007. Although the magnitude of the change was smaller, the shrinking pattern was also clearly observed at the eighth grade (TIMSS 1995: 50\% vs. TIMSS 2007: 36\%). Comparatively, the change in the proportions of school-level differences across the years was smaller at the fourth grade level (TIMSS 1995: 16\% vs. TIMSS 2007: $21 \%$ ) and nearly maintained at the same level at the eighth grade level (TIMSS 1995: $25 \%$ vs. TIMSS 2007: 25\%). In fact, a greater change was revealed at the 
national level. The proportion of national level differences at the fourth grade in TIMSS 2007 (54\%) is more than twice that in TIMSS $1995(26 \%)$ and about 1.5 times that at the eighth grade (TIMSS 1995: 25\% vs. TIMSS 2007: 39\%).

Similar to Zopluoglu's (2012) findings, Uno's (2013) analysis with PISA mathematical literacy data also revealed that the differences of students' performances largely occurred at the individual student level. However, some inconsistences were also revealed in the PISA-based investigation. For instance, the proportion of student-level differences nearly remained at the similar level from PISA $2003(56 \%)$ to PISA 2012 (54\%). While Zopluoglu's TIMSS-based study found that the proportion of national level differences generally increased, Uno reported that the differences in students' mathematics performance in PISA occurred at the national level decreased between 2003 (16\%) to $2012(10 \%)$. Two differences in the research design between TIMSS and PISA may be related to these results: content focus and grade level. More investigations are needed for clarification. Furthermore, another common pattern can be found from Zopluoglu's study of TIMSS data and Uno's study of PISA data. Both found that the differences at the school level revealed a tendency to widen.

\subsection{Final Remarks}

It is clear that inequity in mathematics learning could be associated with individual students' personal characteristics (e.g., gender, family socioeconomic status, immigrant background) and their combinations. Inequity is also related to the countries, the schools, and the communities where the students are studying and living, which, to a certain extent, can be regarded as a concentration of effects. Although general large-scale international student assessments such as PISA and TIMSS may not be the best means to pinpoint the origin of the differences in students' mathematics learning outcomes, they may be the best means to observe changes in the differences in students' mathematics achievement (Forgasz 2010). Flores (2007) made a comment that efforts to document and eliminate the achievement gap are appropriate and necessary, as achievement gap is more of a symptom than a root issue.

On the other hand, while most equity-based mathematics education research appears to focus on "gap gazing", Lubienski and Gutiérrez (2008) have called for a broader focus to address equity issues such as identity and experience. Referring to Gutiérrez's (2009) four-dimension model of equity, equity-based research in mathematics education should move beyond the "dominant axis (i.e., access and achievement) and include the "critical axis" (i.e., identity and power) so as to allow students not only to play with mathematics but also to change mathematics. 


\section{References}

Adamson, F. M. (2010). How does context matter? Comparing achievement scores, opportunities to learn, and teacher preparation across socio-economic quintiles in TIMSS and PISA (Unpublished doctoral dissertation). Stanford University, Stanford.

Andon, A., Thompson, C. G., \& Becker, B. J. (2014). A quantitative synthesis of the immigrant achievement gap across OECD countries. Large-scale Assessments in Education, 2(7), 1-20.

Arnaud, A. J. (2001). Equity. In N. J. Smelser \& P. B. Paultes (Eds.), International encyclopedia of social and behavioral sciences (Vol. 7, pp. 4729-4734). Amsterdam: Elsevier.

Arnesson, R. J. (2001). Equality: Philosophical aspects. In N. J. Smelser \& P. B. Paultes (Eds.), International encyclopedia of social and behavioral sciences (Vol. 7, pp. 4724-4729). Amsterdam: Elsevier.

Baker, D. P., \& Jones, D. P. (1993). Creating gender equality: Cross-national gender stratification and mathematical performance. Sociology and Education, 66, 91-103.

Baker, D. P., \& Wiseman, A. W. (2005). The declining significance of gender and the rise of egalitarian mathematics education. In D. P. Baker \& G. K. LeTendre (Eds.), National differences, global similarities: World culture and the future of schooling (pp. 16-33). Stanford, CA: Stanford University Press.

Baye, A., \& Monseur, C. (2016). Gender differences in variability and extreme scores in an international context. Large-scale Assessments in Education, 4(1), 1-16.

Bishop, A. (2006). The transition experience of immigrant secondary school students: Dilemmas and decisions. In G. de Abreu, A. J. Bishop \& N. C. Presmeg (Eds.), Transitions between contexts of mathematics practices (pp. 53-79). Dordrecht: Kluwer Academic Publishers.

Brown, K. (2006). "New" educational injustices in the "new" South Africa: A call for justice in the form of vertical equity. Journal of Educational Administration, 44(5), 509-519.

Castles, M. J., \& Miller, S. (2003). The age of migration (3rd ed.). Basingstoke: Palgrave Macmillan.

Clancy, P., \& Goastellec, G. (2007). Exploring access and equity in higher education: Policy and performance in a comparative perspective. Higher Education Quarterly, 61(2), 136-154.

Coessens, K., Francois, K., \& Van Bendegem, J. P. (2014). Olympification versus aesthetization: The appeal of mathematics outside the classroom. In P. Smeyers \& M. Depaepe (Eds.), Educational research: Material culture and its representation (Vol. 8, pp. 163-178). Switzerland: Springer International Publishing.

Coleman, J. S., Campbell, E. Q., Hobson, C. J., McPartland, J., Mood, A. M., Weinfeld, F. D., et al. (1966). Equality of educational opportunity. Washington, DC: Government Printing Office.

Damarin, S. (1995). Gender and mathematics from a feminist standpoint. In W. G. Secada, E. Fennema, \& L. B. Adajian (Eds.), New directions for equity in mathematics education (pp. 242-257). New York: Cambridge University Press.

Ellison, G., \& Swanson, A. (2010). The gender gap in secondary school mathematics at high achievement levels: Evidence from the American mathematics competition. The Journal of Economic Perspectives, 24(2), 109-128.

Fennema, E. (1974). Mathematics learning and the sexes: A review. Journal for Research in Mathematics Education, 5, 126-139.

Fennema, E. (2000, May). Gender and mathematics: What is known and what do I wish was known? Paper presented at the 5th annual forum of the National Institute for Science Education. Detroit, MI.

Fennema, E., \& Sherman, J. (1977). Sex-related differences in mathematics achievement, spatial visualization and affective factors. American Educational Research Journal, 14, 51-71.

Field, S., Kuczera, M., \& Pont, B. (2007). No more failures: Ten steps to equity in education. Paris: OECD.

Flores, A. (2007). Examining disparities in mathematics education: Achievement gap or opportunity gap? The High School Journal, 91(1), 1-15.

Forgasz, H. J., Becker, J. R., Lee, K., \& Steinthorsdottir, O. (Eds.). (2010). International perspectives on gender and mathematics education. Charlotte, NC: Information Age Publishing. 
Forgasz, H. J., \& Hill, J. C. (2013). Factors implicated in high mathematics achievement. International Journal of Science and Mathematics Education, 11, 481-499.

Forgasz, H., \& Leder, G. (2001). "A+ for girls, B for boys": Changing perspectives on gender equity in mathematics. In B. Atweh, H. Forgasz, \& B. Nebres (Eds.), Sociocultural research on mathematics education (pp. 347-366). Mahwah: Erlbaum.

Forgasz, H., \& Rivera, F. (Eds.). (2012). Towards equity in mathematics education: Gender, culture and diversity. Heidelberg: Springer.

Grouws, D. A. (Ed.). (1992). Handbook of research on mathematics teaching and learning. New York: Macmillan.

Guiso, L., Monte, F., Sapienza, P., \& Zingales, L. (2008). Culture, gender, and math. Science, 320, $1164-1165$

Gutiérrez, R. (2007). Context matters: Equity, success, and the future of mathematics education. In T. S. Lamberg \& L. R. Wiest (Eds.), Proceedings of the 29th Annual Conference of the North American Chapter of the International Group for the Psychology of Mathematics Education (pp. 1-18). Lake Tahoe, NV: University of Nevada.

Gutiérrez, R. (2009). Framing equity: Helping students "play the game" and "change the game". Teaching for Excellence and Equity in Mathematics, 1(1), 5-8.

Gutiérrez, R. (2010). The sociopolitical turn in mathematics education. Journal for Research in Mathematics Special Equity Issue, 1-32.

Gutiérrez, R., \& Dixon-Román, E. (2011). Beyond gap gazing: How can thinking about education comprehensively help us (re)envision mathematics education? In B. Atweh, M. Graven, W. Secada, \& P. Valero (Eds.), Mapping equity and quality in mathematics education (pp. 21-34). New York, NY: Springer.

Gutstein, E. (2000). Increasing equity: Challenges and lessons from a state systemic initiative. In W. G. Secada (Ed.), Changing the faces of mathematics: Perspectives on multiculturalism and gender equity (pp. 25-36). Reston, VA: NCTM Publishing.

Gutstein, E., Middleton, J. A., Fey, J. T., Larson, M., Heid, M. K., Dougherty, B., et al. (2005). Equity in school mathematics education: How can research contribute? Journal for Research in Mathematics Education, 36(2), 92-100.

Halpern, D. F., Wai, J., \& Saw, A. (2005). A psychobiosocial model: Why females are sometimes greater than and sometimes less than males in math achievement. In A. M. Gallagher \& J. C. Kaufman (Eds.), Gender differences in mathematics: An integrative psychological approach (pp. 48-72). Cambridge: Cambridge University Press.

Hanna, G. (2000). Declining gender differences from FIMS to TIMSS. International Reviews on Mathematical Education, 32(1), 11-17.

Hanna, G. (2003). Reaching gender equity in mathematics education. The Educational Forum, 67, 204-214.

Harlen, W. (2001). The assessment of scientific literacy in the OECD/PISA project. Studies in Science Education, 36, 79-104.

Harnisch, D. L., Steinkamp, M. W., Tsai, S., \& Walberg, H. J. (1986). Cross-national differences in mathematics attitude and achievement among seventeen-year-olds. International Journal of Educational Development, 6(4), 233-244.

Hastedt, D. (2016). Mathematics achievement of immigrant students. Amsterdam, The Netherlands: Springer.

Herrera, L. M. (2007). Equity, equality and equivalence-A contribution in search for conceptual definitions and a comparative methodology. Revista Espanola de Education Comparada, 13, 319-340.

Husén, T. (Ed.). (1967). International study of achievement in mathematics: A comparison of twelve countries (Vols. I \& II). New York: Wiley.

Hutmacher, W. (2001). Introduction. In W. Hutmacher, D. Cochrance, \& N. Bottani (Eds.), In pursuit of equity in education (pp. 1-22). Dordrecht: Kluwer Academic Publishers.

Hyde, J. S., \& Mertz, J. E. (2009). Gender, culture, and mathematics performance. Proceedings of the National Academy of Sciences, 106, 8801-8807.

Kaiser, G. (2003). Feminist frameworks for researching mathematics. In N. Pateman, B. Dougherty, \& J. Zilliox (Eds.), Proceedings of the 2003 Joint Meeting of PME and PMENA (Vol. 1, pp. 157-160). Honolulu: University of Hawaii. 
Kane, J. M., \& Mertz, J. E. (2011). Debunking myths about gender and mathematics performance. Notices of the American Mathematical Society, 59(1), 10-21.

Kao, G., \& Thompson, J. S. (2003). Racial and ethnic stratification in educational achievement and attainment. Annual Review of Sociology, 29, 417-442.

Keeves, J. (1973). Differences between the sexes in mathematics and science courses. International Review of Education, 19, 47-62.

Knapp, M. S., \& Woolverton, S. (2004). Social class and schooling. In J. A. Banks \& C. A. M. Banks (Eds.), Handbook of research on multicultural education (2nd ed., pp. 50-69). San Francisco, CA: Jossey-Bass.

Leder, G. C. (1992). Mathematics and gender: Changing perspectives. In D. A. Grouws (Ed.), Handbook of research on mathematics teaching and learning (pp. 597-622). New York: Macmillan.

Lerman, S. (2000). The social turn in mathematics education research. In J. Boaler (Ed.), Multiple perspectives on mathematics teaching and learning (pp. 19-44). Westport: Ablex Publishing.

Lerman, S. (2006). Cultural psychology, anthropology and sociology: The developing 'strong' social turn. In J. Maasz \& W. Schloeglmann (Eds.), New mathematics education research and practice (pp. 171-188). Rotterdam: Sense.

Lester, F. K. (Ed.). (2007). Second handbook of research on mathematics teaching and learning. Greenwich, CT: NCTM/Information Age.

Lingard, B., Martino, W., Mills, M., \& Bahr, M. (2002). Addressing the educational needs of boys. Canberra, Australia: Commonwealth Department of Education, Science and Training.

Lipman, P. (2004, April). Regionalization of urban education: The political economy and racial politics of Chicago-metro region schools. Paper presented at the annual meeting of the American Educational Research Association, San Diego, CA.

Lubienski, S. T., \& Gutiérrez, R. (2008). Bridging the gaps in perspectives on equity in mathematics education. Journal for Research in Mathematics Education, 39(4), 365-371.

Maccoby, E. E., \& Jacklin, C. N. (1974). Gender segregation in childhood. In H. W. Reese (Ed.), Advances in child development and behavior (Vol. 20, pp. 239-288). New York: Academic Press.

Morely, L., Leach, F., \& Lugg, R. (2009). Democratising higher education in Ghana and Tanzania: Opportunity structures and social inequalities. International Journal of Educational Development, 29, 56-64.

National Council of Teachers of Mathematics (NCTM). (2000). Principles and standards for school mathematics. Reston, VA: Author.

Organization for Economic Cooperation and Development (OECD). (2005). PISA 2003 technical report. Paris: Author.

Organization for Economic Cooperation and Development (OECD). (2012). Equity and quality in education: Supporting disadvantaged students and schools. OECD Publishing. http://dx.doi. org/10.1787/9789264130852-en.

Organization for Economic Cooperation and Development (OECD). (2013a). PISA 2012 results: Excellence through equity (Vol. II). Paris: OECD Publishing.

Organization for Economic Cooperation and Development (OECD). (2013b). PISA 2012 results: Students' engagement, drive and self-beliefs (Vol. III). Paris: OECD Publishing.

Organization for Economic Cooperation and Development (OECD). (2015). PISA in focus. Paris: OECD Publishing.

Pais, A. (2012). A critical approach to equity. In O. Skovsmose \& B. Greer (Eds.), Opening the cage: Critique and politics of mathematics education (pp. 49-92). Sense Publishers.

Rogers, P., \& Kaiser, G. (Eds.). (1995). Equity in mathematics education: Influences of feminism and culture. London: The Falmer Press.

Rohn, D. (2013). Equity in education: The relationship between race, class, and gender in mathematics for diverse learners. Urban Education Research and Policy Annuals, 1(1), 12-22.

Rothman, S., \& McMillan, J. (2003). Influences on academic in literacy and numeracy. Research Report 36. Camberwell, VIC: ACER.

Secada, W. G. (1989). Educational equity versus equality of education: An alternative conception. In W. G. Secada (Ed.), Equity and education (pp. 68-88). New York: Falmer. 
Secada, W. G., Fennema, E., \& Adajian, L. (Eds.). (1995). New directions for equity in mathematics education. Cambridge, USA: Cambridge University Press.

Sirin, S. R. (2005). Socioeconomic status and academic achievement: A meta-analysis. Review of Educational Research, 75(3), 417-453.

Spielman, L. J. (2008). Equity in mathematics education: Unions and intersections of feminist and social justice literature. ZDM Mathematics Education, 40, 647-657.

Steinkamp, M. W., Harnisch, D. L., Walberg, H. L., \& Tsai, S. (1985). Cross-national gender differences in mathematics attitude and achievement among 13-year-olds. The Journal of Mathematical Behavior, 4, 259-277.

United Nations Development Programme. (2009). Human development report 2009 overcoming barriers: Human mobility and development. New York: Author.

United Nations Educational, Scientific and Cultural Organization (UNESCO). (2008). Education for all global monitoring report 2009. Oxford, UK: Oxford University Press.

Uno, M. (2013). National institutional context and educational inequality: A multilevel analysis of variance in family SES effects on academic achievement across OECD countries (Unpublished doctoral dissertation). University of Minnesota, Minneapolis.

Valero, P., Graven, M., Jurdak, M., Martin, D., Meaney, T., \& Penteado, M. (2015). Socioeconomic influence on mathematical achievement: What is visible and what is neglected. In Cho S. J. (Ed.), The Proceedings of the 12th International Congress on Mathematical Education: Intellectual and Attitudinal Challenges (pp. 285-301). New York: Springer.

Valero, P., \& Meaney, T. (2014). Trends in researching the socioeconomic influences on mathematics achievement. ZDM Mathematics Education, 46(7), 1-10.

Volmink, J. (1994). Mathematics by all. In S. Lerman (Ed.), Cultural perspectives on the mathematics classroom (pp. 51-67). Norwell, MA: Kluwer.

Weiner, G., Arnot, M., \& David, M. (1997). Is the future female? Female success, male disadvantage, and changing gender patterns in education. In A. H. Halsey, P. Brown, H. Lauder, \& A. S. Wells (Eds.), Education, economy, culture, and society (pp. 620-630). Oxford: Oxford University Press.

West, C., \& Zimmeran, D. H. (1987). Doing gender. Gender and Society, 1, 125-151.

Wider, G. Z., \& Powell, K. (1989). Sex differences in test performance: A survey of the literature (College Board Report No. 89-3). New York: College Entrance Examination Broad.

Willingham, W. W., \& Cole, N. S. (1997). Gender and fair assessment. Hillsdale, NJ: Erlbaum.

Wood, E., Levinson, M., Postlethwaite, K., \& Black, A. (2011). Equity matters. Brussels: EI. EN/ FR.

Zopluoglu, C. (2012). A cross-national comparison of intra-class correlation coefficient in educational achievement outcomes. Egitimde ve Psikolojide Olcme ve Degerlendirme Dergisi, $3(1), 242-278$.

Open Access This chapter is licensed under the terms of the Creative Commons Attribution 4.0 International License (http://creativecommons.org/licenses/by/4.0/), which permits use, sharing, adaptation, distribution and reproduction in any medium or format, as long as you give appropriate credit to the original author(s) and the source, provide a link to the Creative Commons license and indicate if changes were made.

The images or other third party material in this chapter are included in the chapter's Creative Commons license, unless indicated otherwise in a credit line to the material. If material is not included in the chapter's Creative Commons license and your intended use is not permitted by statutory regulation or exceeds the permitted use, you will need to obtain permission directly from the copyright holder.

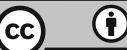

